\title{
Pluralism about Knowledge
}

Robin McKenna

University of Vienna

rbnmckenna@gmail.com

\begin{abstract}
In this paper I consider the prospects for pluralism about knowledge, that is, the view that there is a plurality of knowledge relations. After a brief overview of some views that entail a sort of pluralism about knowledge, I focus on a particular kind of knowledge pluralism I call standards pluralism. Put roughly, standards pluralism is the view that one never knows anything simpliciter. Rather, one knows by this-or-that epistemic standard. Because there is a plurality of epistemic standards, there is a plurality of knowledge relations. In $\$ 1 \mathrm{I}$ argue that one can construct an impressive case for standards pluralism. In $\$ 2$ I clarify the relationship between standards pluralism, epistemic contextualism and epistemic relativism. In \$3 I argue that standards pluralism faces a serious objection. The gist of the objection is that standards pluralism is incompatible with plausible claims about the normative role of knowledge. In \$4 I finish by sketching the form that a standards pluralist response to this objection might take.
\end{abstract}

\section{Introductory Remarks}

Monism about some property $\mathrm{P}$ or relation $\mathrm{R}$ is the view that there is a single $\mathrm{P}$-property or $\mathrm{R}$ relation. Pluralism about $\mathrm{P}$ or $\mathrm{R}$ is the view that there is a plurality of P-properties or R-relations. There is a burgeoning literature on whether we should be monists or pluralists about truth (see, for instance, Lynch 2009; Pedersen and Wright 2013; Wright 1992). In this paper I explore whether we should be monists or pluralists about knowledge. The standard view in epistemology is that the knowledge relation is a two-place relation between a subject $\mathrm{S}$ and a proposition $p$ of the form $\mathrm{K}(\mathrm{S}, p) .{ }^{1}$ The knowledge monist says that there is a single knowledge relation of this form. The knowledge pluralist says that there is a plurality of knowledge relations of this form. I will focus on a kind of knowledge pluralism I call standards pluralism. Put roughly, standards pluralism is the view that one never knows anything simpliciter. Rather, one knows relative to this or that epistemic

\footnotetext{
${ }^{1}$ There is some dissent on this (see e.g. Schaffer 2004a). I comment on this further in fn. 11 and fn. 17.
} 
standard. Because there is a plurality of epistemic standards, there is a plurality of knowledge relations (knowing relative to this standard, knowing relative to that standard, and so on).

Many readers will already be wondering about the connection between standards pluralism and two familiar views in contemporary epistemology. The first view is epistemic contextualism, according to which utterances of sentences of the form "S knows that $p$ " express different propositions in different contexts of utterance (see Blome-Tillmann 2014; Cohen 1999; DeRose 2009; Lewis 1996). For instance, in a context where low epistemic standards are appropriate, the proposition expressed would be something like $S$ knows that $p$ by low standards, whereas in a context where high standards are appropriate it would be something like $S$ knows that $p$ by high standards. The basic difference between these views is that standards pluralism is a metaphysical thesis about the knowledge relation whereas epistemic contextualism is a linguistic thesis about utterances of sentences containing the "knows".

The second view is epistemic relativism, according to which one is never justified in believing something (or never knows anything) simpliciter, but only relative to this or that epistemic system, and there is a plurality of epistemic systems, all of equal validity (for a defence see Kusch forthcoming; for a critique see Boghossian 2006). The basic difference between these views is that, while both 'relativise' knowledge to something (epistemic systems, epistemic standards), the epistemic relativist insists that all systems are equally valid, whereas the standards pluralist does not insist that all standards are equally valid.

Here is the plan. In $\$ 1$ I start by reviewing some views that either involve or seem to entail a kind of pluralism about knowledge. I then introduce standards pluralism, and construct a case for it that largely parallels the case for contextualism. In $\$ 2$ I address the question of the relationship between standards pluralism, contextualism and epistemic relativism. In \$3 I argue that standards pluralism faces a serious objection. The gist of the objection is that standards pluralism is incompatible with plausible claims about the normative role of knowledge. In $\$ 4$ I finish by sketching the form that a standards pluralist response to this objection might take.

Before continuing, I want to say a little more about the motivations for my project. First, my aim is to outline what can be said for and against pluralism about knowledge. Accordingly, my conclusion will be somewhat inconclusive: there is plenty to be said for pluralism about knowledge, but there is also plenty to be said against it. Nevertheless, I intend this paper to be a spur to further work on this topic. 
Second, the literature on the semantics and pragmatics of knowledge ascription is at something of an impasse. The costs and benefits of the various views are well-understood, but different authors disagree as to how they should be weighed up. It is my view that approaching these issues from a rather different angle — at the level of metaphysics rather than semantics — will help to advance the debate. While contextualism does not entail standards pluralism, or vice versa, it is worth considering the prospects for one in light of the prospects for the other. To the extent that this paper gives us reason to be optimistic/pessimistic about the prospects for standards pluralism, it gives us reason to be equally optimistic/pessimistic about the prospects for contextualism.

\section{The Case for Knowledge Pluralism}

I will start with some clarifications and a review of some relevant literature (\$1.1). I then introduce standards pluralism (\$1.2) and try to make a case for it (\$1.3).

\subsection{Types of Epistemic Pluralism}

First, I am interested in pluralism about propositional knowledge, that is, knowledge-that. It is plausible (though not uncontroversial; see e.g. Stanley 2011) that some types of knowledge are non-propositional, e.g. knowledge-how, knowledge-whether etc. While this is a sort of pluralism about knowledge, it is not the kind of pluralism I am interested in.

Second, pluralism about knowledge should not be confused with the truism that there are many ways of knowing a proposition. I might know that my glasses are on the kitchen table because I can see them or because I remember leaving them there. But it would be odd to say that this shows there are two different knowledge relations, knowing-through-perception and knowing-throughmemory. Rather, there are two ways in which one can come to stand in the same relation. What they have in common is, roughly, that they are cognitive successes of the same kind. To say that one can know $p$ through perception or memory is to say that there are different routes to the same success. In contrast, to say that there is a plurality of knowledge relations is to say that there are different relations that are successful in different ways.

There are two kinds of pluralism about epistemic properties and relations that are familiar in epistemology. The first is pluralism about justification. For instance, consider William Alston's $(1993 ; 2005)$ view that there are several 'desiderata' for a theory of justification, but no one property that can satisfy all these desiderata. For instance, a belief may have the property of being produced by a reliable process, thereby satisfying a reliabilist desideratum, yet lack the property of resulting from the satisfaction of some doxastic obligation, thereby failing to satisfy a deontological 
desideratum. If we assume that justification (of whatever variety) entails knowledge, this seems to entail a sort of pluralism about knowledge.

The second is Ernest Sosa's (2007; 2009) distinction between animal and reflective knowledge. Sosa says that a belief qualifies as animal knowledge just in case it is apt, which means that it is correct because of an exercise of cognitive skill by the believer, whereas a belief qualifies as reflective knowledge just in case it is meta-apt, that is, aptly held to be apt, which means that the believer has acquired a perspective on her belief from which they can reflectively endorse the reliability of the faculties that produced it. Animal knowledge is relatively easy to obtain. Joanie has animal knowledge that she has hands so long as she correctly believes that she has hands as a result of the reliable functioning of her perceptual system. Reflective knowledge is a lot harder. Joanie may lack reflective knowledge that she has hands because she can't reflectively endorse the reliability of her perceptual system (she is plagued by sceptical doubts). So animal knowledge and reflective knowledge are two distinct relations that one can stand in to a proposition $p$. Sosa's distinction leads to a kind of knowledge pluralism. ${ }^{2}$

\subsection{Standards Pluralism}

My focus in this paper is on a kind of knowledge pluralism I call 'standards pluralism'. Put roughly, standards pluralism is the view that one can never know anything simpliciter. Rather, one only knows relative to this or that epistemic standard. Say that the set of epistemic standards is $\left\{\mathrm{E}_{1}, \mathrm{E}_{2} \ldots \mathrm{E}_{\mathrm{N}}\right\}$. Standards pluralists hold that there is a plurality of knowledge relations of the form $\mathrm{K}_{\mathrm{Ei}}(\mathrm{S}, p)$. In the rest of this section I will say a little bit more about standards pluralism, explain how it differs from both Alston's and Sosa's brand of pluralism, and outline the motivations behind it.

We can start with the idea of some subject S's 'strength of epistemic position' with respect to some proposition $p$. How strong S's epistemic position with respect to $p$ is depends on things like how much evidence $\mathrm{S}$ has for $p$, how reliable S's belief-forming processes are, and so on. How strong does S's epistemic position with respect to $p$ need to be for $S$ to know that $p$ ? The knowledge monist holds that there is a unique strength of epistemic position required (though monists will differ on what that strength is). Because there is a unique strength of epistemic position required for knowledge, one can talk about $\mathrm{S}$ as either knowing or not knowing simpliciter. If S's epistemic

\footnotetext{
${ }^{2}$ While Sosa denies that the word "knows" is ambiguous (see 2009, 135), this is no reason to deny that Sosa is a knowledge pluralist. Many truth pluralists deny that "true" is ambiguous (see Alston 2002; Lynch 2009; Wright 1996).
} 
position is strong enough, they know; if it isn't, they don't. The standards pluralist holds that there cannot be a unique strength of epistemic position required for knowledge (for their reasons why, see below). Because there is not a unique strength required, one cannot talk about $\mathrm{S}$ as either knowing or not knowing simpliciter. However, one can talk about whether S's epistemic position is strong enough to satisfy this-or-that epistemic standard. The standards pluralist says that, if S's epistemic position satisfies standard $\mathrm{E}$, then $\mathrm{S}$ knows relative to $\mathrm{E}$. We can think of epistemic standards as lying on a continuum, with the highest standards requiring the strongest possible epistemic position for knowledge, and lower standards requiring weaker epistemic positions.

Standards pluralism differs from Alston's brand of pluralism in that it is based on the thought that one can know relative to one epistemic standard but not relative to another, not the thought that there are different desiderata one might want one's account of knowledge (or justification) to meet. It would be wrong to construe 'reliabilist knowledge' (knowledge as something produced by a reliable belief forming process) as 'knowledge by low standards' and 'deontological knowledge' (knowledge as something requiring the meeting of doxastic obligations) as "knowledge by low standards' (or vice versa). These are different conceptions of what it is to know, not cognitive states that can be ranked in terms of the strength of epistemic position required to instantiate them. While one could construe Sosa's distinction between animal and reflective knowledge in terms of epistemic standards - animal knowledge is 'low grade' knowledge whereas reflective knowledge is 'high grade' knowledge- the operative notion of epistemic standard is rather different from the standards pluralist's notion of epistemic standard. Reflective knowledge is 'higher grade' in the sense that it involves a kind of perspective on one's first-order beliefs. One's epistemic position is stronger when one has reflective knowledge than when one has mere animal knowledge, but the difference is one of kind, not degree.

The main motivation for standards pluralism is that it can resolve three puzzles. First, consider this pair of cases:

LOW: Hannah and her wife Sarah are driving home on a Friday afternoon. They plan to stop at the bank on the way home to deposit a check. It's not important that they do so, as they have no impending bills. But, as they drive past the bank, they notice that the lines inside are very long. Realising that it isn't very important that the check is deposited right away, Hannah says, 'I know that the bank will be open tomorrow. I was there just two weeks ago on Saturday morning. So we can deposit our check tomorrow morning?. 
HIGH: Same setup, but here Hannah and Sarah have an impending bill and very little in their account, so it's very important that they deposit their check by Saturday. Hannah notes that she was at the bank two weeks before on a Saturday morning, and it was open. But, as Sarah points out, banks do change their hours. Hannah says, 'I guess you're right. I don't know that the bank will be open tomorrow' (Stanley 2005, 3-4; for the original cases see DeRose 1992).

Intuitively, Hannah's knowledge ascription in LOW and her knowledge denial in HIGH are both true. But her epistemic position is no stronger in HIGH than in LOW. This raises a problem. If we assume that any given epistemic position is either strong enough or not strong enough for knowledge, we must choose: Hannah either knows in LOW and HIGH, or does not know in either. The standards pluralist solves the problem by rejecting this assumption. One can only know relative to this-or-that standard, and any given epistemic position can be strong enough to satisfy one standard but not strong enough to satisfy another. Thus, the standards pluralist doesn't need to choose. In LOW Hannah and Sarah adopt an epistemic standard based on their needs, interests and purposes (they want to cash the check but it isn't urgent). Call this standard $\mathrm{E}_{\mathrm{Low}}$. Hannah's epistemic position is strong enough to satisfy $\mathrm{E}_{\mathrm{LON}}$, so she knows that the bank is open on Saturdays relative to $\mathrm{E}_{\mathrm{Low}}$. Now take HIGH. Hannah and Sarah adopt a different epistemic standard based on their different needs, interests and purposes (it is now urgent that they cash the check). Call this $\mathrm{E}_{\text {HIGH }}$. Hannah's epistemic position is not strong enough to satisfy $\mathrm{E}_{\mathrm{HIGH}}$, so she does not know relative to $\mathrm{E}_{\text {нIGн. }}$. If we specify the different knowledge relations involved, the puzzle evaporates.

Second, consider this inconsistent triad:

1) Joanie knows that she has hands.

2) If Joanie knows that she has hands, she knows that she is not a handless brain in a vat.

3) Joanie does not know that she is not a handless brain in a vat.

Imagine Joanie has the usual kind of evidence that she has hands. The anti-sceptic argues, convincingly, that 1) is true. If Joanie doesn't know this, what does she know? The sceptic argues, also convincingly, that 3 ) is true. How could Joanie know that she is not a handless brain in a vat, given that she seems unable to rule sceptical hypotheses out? ${ }^{3}$ ) is common-ground between the

\footnotetext{
${ }^{3}$ Of course, this is controversial. I am following the standard setup of the sceptical problem in the contextualist literature (see, for example, DeRose 1995).
} 
sceptic and the anti-sceptic. ${ }^{4}$ This raises a problem. If we assume that any given epistemic position is either strong enough or not strong enough for knowledge, we must choose between antiscepticism and scepticism. Joanie either does not know that she has hands, or she does know that she is not a handless brain in a vat. Again, the standards pluralist solves the problem by rejecting this assumption, and so 'splits the difference' between the anti-sceptic and the sceptic. Who is 'right' depends on which epistemic standard is appropriate given our needs, interests and purposes. Imagine that Joanie has recently had an accident and is checking that everything is in working order. She looks down and sees hand-shaped objects. Her epistemic position is strong enough to satisfy the epistemic standard appropriate to her purpose. So she knows that she has hands relative to this standard. Now imagine that Joanie is discussing Descartes' Meditations with Chris. Chris is pushing the line that Joanie can't rule out Descartes' sceptical scenarios. Her epistemic position is not strong enough to satisfy the epistemic standard appropriate to this purpose. So she does not know that she has hands relative to this standard. Where both the sceptic and anti-sceptic go wrong is in assuming that Joanie either knows or does not know simpliciter.

Third, consider what Laurence Bonjour (2010) calls the 'threshold problem'. For the sake of argument let's assume that knowledge is non-accidental justified true belief. A problem arises for those who want to combine two popular claims:

- Fallibilism: S may know that $p$ on the basis of justification that does not guarantee the truth of $p$.

- Knowledge is a very valuable and desirable cognitive state. ${ }^{5}$

If knowledge does not require justification that guarantees the truth of the relevant belief, what level of justification does it require? Bonjour says that "it is very difficult or, I believe, impossible to see what could give any level of justification that is short of being conclusive the kind of special significance that [fallibilism] requires it to have." $(2010,61)$. The point is not that we couldn't decide that there is some threshold $\mathrm{t}$ such that, if S truly believes that $p$ on the basis of

\footnotetext{
${ }^{4}$ That is, they both accept the principle that knowledge is closed under known entailment: if S knows that $p$, and knows that $p$ entails $q$, then $\mathrm{S}$ knows that $q$. For defences of closure principles see DeRose (1995); Hawthorne (2004); Williamson (2000). For criticisms see Dretske (2005). ${ }^{5}$ Of course, some epistemologists deny fallibilism (for instance, Williamson 2000), and some deny that knowledge is particularly valuable or desirable (for instance, Kaplan 1985). But Williamsonian infallibilism is highly controversial (see Brown 2013) and, while BonJour talks as if the problem requires holding that knowledge is the supremely valuable and desirable cognitive state, it is enough to hold that knowledge is merely very valuable.
} 
justification that is at least as strong as $t$, then $\mathrm{S}$ knows that $p$. Rather, the point is that any choice of $\mathrm{t}$ would be largely arbitrary, and so it would be implausible to hold that the difference between true belief based on justification that is at least as strong as $t$ and true belief based on justification weaker than $t$ marks a difference in value. ${ }^{6}$ Thus, it is hard to combine fallibilism with the claim that knowledge is valuable. If, like Bonjour, we assume that knowledge is valuable, we must conclude that fallibilism is false.

BonJour's discussion implicitly assumes that the fallibilist holds that there is a unique level of justification that is required for knowledge. The standards pluralist rejects this assumption, and so can solve the problem. Even if there is no level of justification that is appropriate in all situations, there may be reasons to privilege particular levels in particular situations. These reasons would give particular levels significance in some situations, but not necessarily any significance in other situations. Take Hannah and Sarah. In LOW their needs, interests and purposes give them a reason to adapt a relatively lax epistemic standard such that Hannah's epistemic position is strong enough to satisfy it. However, in HIGH their different needs, interests and purposes give them a reason to adopt a stricter epistemic standard such that Hannah's epistemic position is not strong enough to satisfy it. On the plausible assumption that people generally have reasons to privilege one standard over another in particular situations, the problem vanishes. ${ }^{7}$

All of these arguments need further development, but I lack the space to pursue this here. My claim is just that standards pluralism offers prima facie plausible responses to all three puzzles. This is not to say that they are ultima facie plausible, or that the standards pluralist responses are preferable to alternatives. ${ }^{8}$ One thing that is striking is how closely the standards pluralist responses parallel the contextualist responses to these puzzles. In the next section I clarify the relationship between standards pluralism and two other views in epistemology: contextualism and epistemic relativism.

\footnotetext{
${ }^{6}$ This is why the threshold problem isn't just about vagueness. Even if there were a sharp boundary between knowledge and its absence, that boundary would be arbitrary, and so wouldn't support a difference in value between knowledge and cognitive states that fall just short of it.

${ }^{7}$ This is just a sketch of the standards pluralist's response to BonJour's threshold problem. For a more developed account that I largely agree with see Grimm (2015); Hannon (2017).

${ }^{8}$ For some alternatives see Brown (2006); Fantl and McGrath (2009); Gerken (2011); Hawthorne (2004); MacFarlane (2014, chap. 8); Nagel (2008); Rysiew (2001); Stanley (2005).
} 


\section{Standards Pluralism, Contextualism and Epistemic Relativism}

I will argue for three claims. First, while the standards pluralist isn't forced to adopt a contextualist semantics for the word "knows", they are forced to adopt some kind of non-standard semantics, like contextualism. Second, while contextualism does not entail standards pluralism, it is good evidence that standards pluralism is true. Third, while both standards pluralism and epistemic relativism relative knowledge to something (standards, systems), they differ in that the standards pluralist does not hold that standards cannot be ranked. I will take each claim in turn.

\subsection{Knowledge Pluralism and the Semantics of Knowledge Ascriptions}

There is an important structural difference between truth pluralism and standards pluralism. According to the truth pluralist, sentences are either true or false, but different properties 'make for' truth in different domains of discourse. For instance, Lynch (2009) proposes a functionalist version of truth pluralism according to which different properties play the 'truth role' in different domains of discourse, in the same way that different physical states might play the 'pain role' for different biological species. Perhaps in discourse about 'medium-sized dry goods' correspondence plays the relevant functional role, whereas in discourse about what is funny the role is played by what Wright (1992) calls 'super-assertability'. In contrast, the standards pluralist does not think that different relations 'make for' knowledge in different domains of discourse. Rather, the view is that, no matter what the domain is, one can only know relative to this-or-that standard.

This structural difference raises a problem. We talk about subjects knowing that $p$, not about subjects knowing that $p$ relative to this-or-that standard. What does the standards pluralist say about knowledge ascriptions of the form "S knows that $p$ "? Consider:

4) Joanie knows that she has hands.

5) Joanie does not know that she has hands.

Does the standards pluralist think that 4) is true? If so, on pain of contradiction they must think that 5) is false. But the idea behind the response to the sceptical puzzle was that 4) is sometimes true and other times false. Clearly, the standards pluralist needs a story about the semantics of knowledge ascriptions such that 4) can sometimes be true and other times be false. In principle, any number of views about the semantics of knowledge ascriptions would serve the standards 
pluralist's purposes here. ${ }^{9}$ For the sake of simplicity, I will opt for a contextualist semantics according to which the word "knows" refers to different relations in different contexts. Take a context where 'everyday' epistemic standards are operative. Utterances of 4) and 5) in such contexts refer to the relation of knowing relative to everyday standards, and because Joanie knows relative to everyday standards, utterances of 4) are true and utterances of 5) are false in such contexts. Now take a context where 'sceptical' standards are operative. Utterances of 4) and 5) in such contexts refer to the relation of knowing relative to sceptical standards, and, because Joanie does not know relative to sceptical standards, utterances of 4) are false and utterances of 5) are true in such contexts.

\subsection{Contextualism as Evidence for Standards Pluralism}

Standards pluralism is a view about the knowledge relation, whereas contextualism is a view about the word "knows". To get a handle on this difference, compare what the two views say about LOW and HIGH. The standards pluralist says that there are two relations, knowing relative to $\mathrm{E}_{\mathrm{LOw}}$ and knowing relative to $\mathrm{E}_{\text {нIGн. }}$. Hannah knows relative to $\mathrm{E}_{\mathrm{LOW}}$ that the bank is open on Saturdays, but does not know relative to $\mathrm{E}_{\text {НІGн. }}$. The contextualist says that Hannah's knowledge ascription in LOW and knowledge denial in HIGH don't express incompatible propositions. In LOW she expresses something like the proposition Hannah knows that the bank is open on Saturdays by $E_{\text {Low }}$; in HIGH she

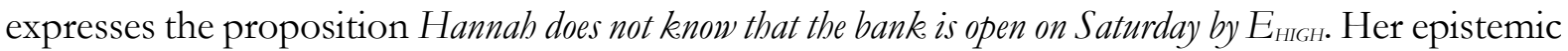
position is such that both propositions are true. ${ }^{10}$

The contextualist's view about the propositions expressed by Hannah's knowledge ascription and denial doesn't entail that there are two relations, knowing relative to $\mathrm{E}_{\mathrm{LOw}}$ and knowing relative to $\mathrm{E}_{\text {HIGH }}$. But, if contextualism is true, it puts pressure on the view that there is a single two-place knowledge relation. If there were a single two-place knowledge relation, then Hannah would either know that the bank is open on Saturdays, or she would not know. But, if Hannah knows, it should be true to say that she "knows" in any context, and if she doesn't know, it should be true to say that she doesn't "know" in any context. The only way to avoid this would be to hold that, even though there is a single two-place knowledge relation, uses of the word "knows" don't always refer

\footnotetext{
${ }^{9}$ The standards pluralist could endorse the kind of Austinian semantics for knowledge ascriptions proposed in Lawlor (2013), the non-indexical contextualism proposed in Brogaard (2008), Kompa (2002) or MacFarlane (2009), and maybe even the assessment relativism proposed in MacFarlane (2014). I lack the space to discuss these options here.

${ }^{10}$ For versions of this account see Cohen (1999) and DeRose 2009).
} 
to it. ${ }^{11}$ But this would mean divorcing the semantics of knowledge ascriptions from the metaphysics of knowledge.

One can buttress this argument by considering the contextualist response to the sceptical problem. Like the standards pluralist, the contextualist tries to 'split the difference' between the sceptic and the anti-sceptic. In some contexts it can be true to say that Joanie "knows" that she has hands, whereas in other contexts it can be true to say that Joanie does not "know" that she has hands. ${ }^{12}$ Now imagine there were just a single two-place knowledge relation. Presumably Joanie either knows that she has hands, or she doesn't. If she knows, scepticism is false. If she doesn't, it is true. Either way, it is unclear how the contextualist can 'split the difference' between the sceptic and the anti-sceptic, irrespective of the correct semantics for the word "knows". 13

I conclude that, while contextualism doesn't entail that standards pluralism is true, it is good evidence that standards pluralism is true.

\subsection{Standards Pluralism and Epistemic Relativism}

By epistemic relativism I mean a metaphysical view about epistemic properties and relations (as in e.g. Boghossian 2006) rather than a view about the semantics of sentences involving epistemic vocabulary (as in e.g. MacFarlane 2014). Discussions of this kind of epistemic relativism usually focus on a view about epistemic justification, according to which one's beliefs can never be justified simpliciter, but only relative to this or that epistemic system, and there is a plurality of epistemic systems, all of equal validity (see, for instance, Boghossian 2006; Kusch forthcoming; Seidel 2014; Williams 2007). But one can consider a structurally analogous view about knowledge, according to which one never knows simpliciter, but only relative to this or that epistemic system, and there is a plurality of epistemic systems, all of equal validity. How does standards pluralism differ from this view?

\footnotetext{
${ }^{11}$ That is, unless the contextualist denies that the knowledge relation is a two-place relation, and proposes instead that is a three-place relation of the form $\mathrm{K}\left(\mathrm{S}, p, \mathrm{E}_{\mathrm{i}}\right)$, where $\mathrm{E}_{\mathrm{i}}$ is a parameter fixed by the context (e.g. an epistemic standard, a contrast class). Hannah's ascription and denial could then refer to the same relation, but in LOW the third argument place is filled by $\mathrm{E}_{\mathrm{Low}}$, whereas in high it is filled by $\mathrm{E}_{\text {нIGн. }}$ Though most contextualists don't take this route, some do (e.g. Schaffer 2004a; Schaffer and Szabo 2013). For further discussion see fn. 17.

${ }^{12}$ For versions of this account see Blome-Tillmann (2014); DeRose (1995); Lewis (1996).

${ }^{13}$ For a similar argument see Schaffer (2004b).
} 
There is a relatively superficial difference. Where the epistemic relativist talks of epistemic systems, the standards pluralist talks of epistemic standards. We can think of epistemic systems as consisting in sets of principles that encode acceptable (and unacceptable) epistemic practice. For instance, our epistemic system tells us that we are entitled to rely on the evidence of our senses absent reason to doubt their reliability. Alternative epistemic systems might tell their adherents that they are entitled to rely on the deliverances of oracles. The crucial contrast between epistemic systems and epistemic standards is that, where epistemic standards mark different degrees or levels of justification that beliefs can enjoy, epistemic systems constitute frameworks against which we can talk of beliefs as being justified in the first place.

There is also a deeper difference. The epistemic relativist holds that all justification is systemrelative and, because it is impossible to provide a non-circular justification for any epistemic system, all these systems are equally valid. The standards pluralist holds that all knowledge is standards-relative. But the kind of standards pluralism considered here does not hold that all these standards are equally valid, or at least it doesn't hold that they are all equally valid in any particular situation. Rather, in any given particular situation some standards are appropriate whereas others are inappropriate. For instance, given Hannah and Sarah's situation in LOW, a low epistemic standard is appropriate, not a high standard; given their different situation in HIGH, a high standard is appropriate, not a low standard. But this requires that all standards are not equally valid. One could say that all standards are appropriate in some situation, but not all standards are appropriate in all situations. While one could consider a version of standards pluralism on which all standards are equally valid, it is unclear whether one could argue for it in the way I have argued for standards pluralism here.

\section{The Case against Standards Pluralism}

In this section I argue that standards pluralism faces a serious objection. The standards pluralist posits a plurality of knowledge relations. But what makes these knowledge relations rather than some other kind of relation? One would expect the answer is that they all have something in common: they satisfy certain conceptual constraints on what can count as a knowledge relation. The objection is that it is, at best, unclear whether the relations posited by the standards pluralist meet these constraints. So it is unclear whether standards pluralism really offers us a theory of knowledge. This challenge parallels a challenge that Michael Lynch (2013) raises for the truth pluralist. So I start with Lynch's articulation of his challenge. 


\subsection{What Makes a Theory of Truth a Theory of Truth?}

Truth pluralism is the view that, while there are properties the instantiation of which makes sentences true, there is a plurality of these properties. But in virtue of what are all of these properties truth properties, as opposed to some other kind of property? Lynch's thought is that there are conceptual constraints on the kinds of properties that the theorist can identify with our pre-theoretic notion of truth. These constraints are captured in three 'core platitudes' about truth:

- Objectivity (OBJ): True propositions are propositions such that, when we believe them, things are as we believe them to be.

- Aim of inquiry (AIM): True propositions are propositions such that we should aim to believe them when engaging in inquiry.

- Norm of Belief (NORM): True propositions are propositions such that they are correct to believe.

A theory that identifies truth with some property $T$ or set of properties $\left\{T_{1}, T_{2} \ldots T_{N}\right\}$ is a theory of truth iff propositions that instantiate $T$ or one of $\left\{\mathrm{T}_{1}, \mathrm{~T}_{2} \ldots \mathrm{T}_{\mathrm{N}}\right\}$ satisfy OBJ, AIM and NORM. Thus, Lynch's challenge for the truth pluralist is to show that propositions that instantiate one of $\left\{T_{1}, T_{2} \ldots T_{N}\right\}$ satisfy OBJ, AIM and NORM. If they can't do that, then it is unclear in what sense they have given us a theory of truth, as opposed to a theory of something else.

Lynch motivates his challenge by appealing to Frank Jackson's (1998) view that our tacit beliefs about the object of a metaphysical inquiry can be codified in a set of platitudes, which put constraints on the subsequent theories about that object that can be developed in the course of inquiry. One might worry that, for any philosophically interesting notion $\mathrm{X}$, there are very few genuine platitudes about $\mathrm{X}$. Take truth. Is it a platitude that truth is the aim of inquiry or the norm of belief? Some have explicitly denied that truth is the aim of inquiry or norm of belief (e.g. Rorty 1995). While we can accuse them of conceptual confusion, or of just talking about something different to the rest of us, these accusations feel strained. Aren't we just fighting about whether to call something a theory of truth or not?

While I admit that this worry has some force, I don't think it necessarily causes a problem for Lynch's challenge. One can tweak Jackson's picture to avoid a commitment to platitudes. Rather than think of OBJ, AIM and NORM as platitudes, we can think of them as principles that codify why we think truth is theoretically important. Truth is theoretically important because of its connection to objectivity (OBJ) and because of its normative role (AIM and NORM). We may call a theory that does not satisfy these platitudes a theory of truth, but it is a theory of truth on which truth is of 
little theoretical interest. If that is what truth is, we might as well stop talking about it. So one can think of Lynch's challenge as a challenge to the theorist to demonstrate that they are giving us an account of some philosophically interesting notion rather than reasons to abandon that notion. While I will stick with Lynch's own understanding of his challenge, I am happy to retreat to this alternative formulation if the reader regards it as necessary.

I will now construct a parallel challenge for the standards pluralist.

\subsection{What Makes a Theory of Knowledge a Theory of Knowledge?}

Just as there are conceptual constraints on the kinds of properties that the theorist can identify with our pre-theoretic notion of truth, there are conceptual constraints on the kinds of relations that the theorist can identify with our pre-theoretic notion of knowledge. If the plurality of relations posited by the standards pluralist don't satisfy these constraints, then it is unclear in what sense they have given us a theory of knowledge, as opposed to a theory of something else.

While I think one can motivate Lynch's challenge on these kinds of general grounds, I want to emphasise that the challenge is particularly pressing for the standards pluralist. Recall that the standards pluralist thinks that there is no such thing as knowing something simpliciter. One might think that, if there is no such thing as knowing simpliciter, we should eliminate the notion of knowledge. But the standards pluralist does not propose eliminating the notion of knowledge. Rather, they propose holding that there is a plurality of knowledge relations. Thus, the burden is on the standards pluralist to show that this is a replacement rather than an elimination of our standard picture of knowledge. If the standards pluralist can answer Lynch's challenge, they have shown this is a replacement. If they can't, the suspicion is that the standards pluralist has really eliminated knowledge, and replaced it with something else entirely.

The first step is to identify the platitudes governing knowledge. Some of these platitudes are of little interest for my purposes. Take, for instance, the platitude that knowledge is factive. This poses no problem for the standards pluralist. The standards pluralist can hold that, while there is a plurality of knowledge relations, all of these relations are factive: if $\mathrm{S}$ knows that $p$ relative to some standard $\mathrm{E}$, then $p$ is true. I am more interested in these three platitudes about the 'normative role' of knowledge:

INQ: If $\mathrm{S}$ knows that $p$ at $\mathrm{t}, \mathrm{S}$ may stop inquiring into whether $p$ at $\mathrm{t}$ (see Kappel 2010; Kelp 2011; Rysiew 2012). 
ACT: If $\mathrm{S}$ knows that $p$ at $\mathrm{t}$, then, usually, $\mathrm{S}$ may treat $p$ as a reason for acting at t. ${ }^{14}$

ASS: If $\mathrm{S}$ knows that $p$ at $\mathrm{t}$, then, usually, $\mathrm{S}$ may assert that $p$ at $\mathrm{t} .{ }^{15}$

The basic thought behind INQ is that knowledge is the natural stopping-point of inquiry. Once an inquiry has yielded knowledge, you may stop. The basic thought behind ACT and ASs is that, if you know some proposition $p$, there is usually no epistemic barrier to you treating $p$ as a reason for acting or asserting that $p$. You may (in the epistemic sense of 'may') treat $p$ as a reason for acting or assert that $p$. I want to make two comments here. First, I have chosen these 'weaker' formulations of ACT and ASs because some have argued that there are cases where knowing some $p$ is insufficient for properly treating $p$ as a reason for acting or asserting that $p$. But these cases are unusual. ${ }^{16}$ Second, for the sake of simplicity, I will assume that there are no other epistemic norms governing inquiry, practical reasoning and assertion. So knowing that $p$ at $\mathrm{t}$ is necessary as well as sufficient for being permitted to terminate inquiry into whether $p$ at $\mathrm{t}$, and knowledge is typically required for proper practical reasoning and assertion.

The second step is to raise Lynch's challenge. There is an initial problem here. The standards pluralist can't accept these platitudes as they stand because they talk about knowledge simpliciter, rather than knowing relative to this-or-that standard. I am going to argue that this initial problem leads to a bigger problem. While there are a number of ways in which the standards pluralist can reformulate the platitudes, all of these ways are either (a) independently implausible or (b) yield platitudes that the vast majority of knowledge relations posited by the standards pluralist fail to satisfy. Thus, the standards pluralist either holds an implausible view about the normative roles of knowledge, or fails to satisfy Lynch's challenge.

Here are three options for the standards pluralist. To make things simple I focus on INQ. But similar remarks can be made about ASS and АСТ. They are:

INQ*: If S knows that $p$ relative to some standard at t, then $\mathrm{S}$ may stop inquiring into whether $p$ at $\mathrm{t}$.

\footnotetext{
${ }^{14}$ For defences of somewhat stronger versions of АCT see Hawthorne and Stanley (2008); Williamson (2005).

${ }^{15}$ For a defence of a somewhat stronger version of ASS see Williamson (2000).

${ }^{16}$ For instance, these are cases where the 'stakes' are unusually high, or one is required to follow certain institutional procedures. For such cases see Brown (2008b, 2008a); Gerken (2011); Lackey (2007).
} 
$\mathrm{INQ}^{* *}$ : If $\mathrm{S}$ knows that $p$ relative to every standard at $\mathrm{t}$, then $\mathrm{S}$ may stop inquiring into whether $p$ at $\mathrm{t}$.

INQ***: If $\mathrm{S}$ knows that $\mathrm{p}$ relative to the relevant standard at $\mathrm{t}$, then $\mathrm{S}$ may stop inquiring into whether $p$ at t.

To evaluate these proposals it will be helpful to consider some cases:

TRAIN STATION: Catriona is getting the train from Edinburgh to Glasgow. She wants to get the fast train, but it isn't particularly important that she does so. Because the fast train has always left from platform 7 and she hasn't heard or seen any announcements to the contrary, she heads to platform 7 and boards the train.

RISKY TRAIN STATION: Same as TRAIN STATION, except that it is vitally important that Catriona catch the fast train because she has a very important appointment that she will otherwise miss.

It seems clear that Catriona may terminate her inquiry into whether the train leaves from platform 7 in TRAIN STATION (she can board the train without asking) but may not terminate her inquiry in RISKY TRAIN STATION (she needs to find out more before boarding). Catriona's epistemic position with respect to the proposition that the fast train leaves from platform 7 is the same in both cases. But, while it is strong enough for the purposes at hand in TRAIN STATION, it is not strong enough for the purposes at hand in RISKY TRAIN STATION. Call the proposition that the fast train leaves from platform 7 'TRAIN', the epistemic standard appropriate in TRAIN STATION 'E $\mathrm{E}_{\mathrm{TS}}$ ' and the standard appropriate in RISKY TRAIN STATION 'E $\mathrm{ETS}_{\text {TS }}$. Catriona knows TRAIN relative to $\mathrm{E}_{\mathrm{TS}}$ but she does not know TRAIN relative to $\mathrm{E}_{\mathrm{RTS}}$. So, in RISKY TRAIN STATION, she knows relative to some standard- $\mathrm{E}_{\mathrm{TS}}$ - but, clearly, can't stop inquiring into whether TRAIN is true. Thus, INQ* is false. The problem with $\mathrm{INQ}^{*}$ is that it is far too weak. A subject can stand in $a$ knowledge relation to some proposition $p$ yet be in no position to stop inquiring into whether $p$.

The problem with INQ** is that it is far too strong. Remember we are assuming that $\mathrm{INQ}^{* *}$ is the only epistemic norm governing inquiry. Thus, it entails that one may terminate inquiry into whether $p$ only if one knows that $p$ relative to any standard whatsoever. The upshot is that we may rarely, if ever, terminate inquiry. Consider this case:

BETTER TRAIN STATION: Same as TRAIN STATION, except that Catriona has asked the ticket inspector who has told her that this is indeed the fast train. 
Plausibly, Catriona both knows relative to the standards appropriate in BETTER TRAIN STATION (whatever else could she do?) and may terminate her inquiry into whether TRAIN is true. But she does not know relative to any standard whatsoever. Consider 'sceptical standards', that is, standards that require Catriona to rule out scenarios in which the ticket inspector is part of a vast conspiracy to trick Catriona into taking the wrong train. Despite having excellent evidence for TRAIN, Catriona can't rule this possibility out. So INQ** is implausibly strong.

The obvious fix to both problems is to require that the subject stand in the relevant knowledge relation (INQ***). At a rough first pass, we can say that the knowledge relation that is relevant for a subject $S$ at a time $t$ is the relation of knowing relative to whatever epistemic standards are appropriate for $\mathrm{S}$ at $\mathrm{t}$. The thought is that something about $\mathrm{S}$ 's practical situation 'picks out' a single knowledge relation as most appropriate. So the relevant knowledge relation for Catriona in RISKY TRAIN STATION is $\mathrm{E}_{\mathrm{RTS}}$, not $\mathrm{E}_{\mathrm{TS}}$. Because Catriona does not know relative to the relevant epistemic standard, it is not the case that Catriona may terminate her inquiry. INQ*** gets the right result.

Even though INQ*** gets the right result, it is unclear whether the standards pluralist who endorses it can answer Lynch's challenge. Remember that the platitudes put conceptual constraints on what can count as a knowledge relation. Platitudes like INQ tell us that knowledge relations have a particular normative role or profile. For instance, INQ tells us that the knowledge relation is a relation such that, when one stands in it to some proposition $p$ at a time $t$, one may terminate inquiry into whether $p$ at t. So one would expect that the pluralist about knowledge posits a set of knowledge relations all of which are such that, when one stands in them to some $p$ at $\mathrm{t}$, one may terminate inquiry into whether $p$ at t. But INQ*** tells us that only the relation of knowing by the relevant epistemic standard is such that, when one stands in it to some $p$ at $t$, one may terminate inquiry into whether $p$ at $\mathrm{t}$. So, at any given time, many of the knowledge relations posited by the standards pluralist don't play the normative roles of knowledge relations. But this means that the standards pluralist can't answer Lynch's challenge, and so it is unclear in what sense they offer a theory of knowledge, rather than a theory of something else. ${ }^{17}$

\footnotetext{
${ }^{17}$ Does the problem arise if there is a single three-place relation of the form $\mathrm{K}\left(\mathrm{S}, p, \mathrm{E}_{\mathrm{i}}\right)$ ? According to this view, the relation of knowing relative to the standard $\mathrm{E}_{\mathrm{TS}}$ and the relation of knowing relative to the standard $\mathrm{E}_{\mathrm{RTS}}$ are not distinct relations. Rather, they are instances of the same relation with different relata. I think that it does. The key question is: what makes all of these instances knowledge relations? Given Lynch's challenge, the answer must be that they are knowledge relations because they satisfy certain conceptual constraints. But the argument just
} 
In conclusion, no matter how the standards pluralist tries to formulate INQ, they face problems. Either the reformulations are implausible, or some of the relations they posit fail to satisfy them. Similar considerations apply to ACT and ASS. I am going to finish by looking at how the standards pluralist could try to respond to this problem. ${ }^{18}$

\section{Sketch of a Response}

The basic idea behind ACT, ASS and INQ is that knowing that $p$ gives one certain rights — to treat $p$ as a reason for acting, to assert that $p$, to terminate one's inquiry into whether $p$ - in a very wide range of situations. The problem for the standards pluralist is that, if you know that $p$ relative to some standard E, this only gives you these rights in a narrower range of situations, viz. situations where $\mathrm{E}$ is the appropriate standard. The only way that the standards pluralist can salvage the basic idea behind ACT, ASS and INQ is if they can find a way to expand the range of situations in which knowing relative to some standard E gives one these rights. I am going to finish by suggesting how the standards pluralist might be able to do this. As before, I will focus on INQ, but similar considerations apply to ACT and ASS.

We can start by thinking about other properties and relations that give one certain rights in a wide, but still circumscribed, set of situations. Take the relationship of being someone's legal guardian. If $\mathrm{X}$ is Y's legal guardian, then $\mathrm{X}$ has various rights. For instance, $\mathrm{X}$ has the right to make certain decisions on Y's behalf; what school Y goes to, what medical treatments they get, etc. But legal guardianship is a status that is bestowed on one by a legal system or framework. Because different countries have different legal systems, it may be that $\mathrm{X}$ is recognised as Y's legal guardian by one system, yet isn't recognised as Y's legal guardian by another system. Thus, the legal guardianship relation gives one certain rights in a wide, but still circumscribed, set of situations. Roughly, one

given tells us that only one instance of this single relation - knowing relative to the relevant epistemic standard - is such that, if one stands in it to some $p$ at $\mathrm{t}$, one may terminate inquiry into whether $p$ at $t$. So, at any given time, many of the instances of this single relation don't satisfy the relevant conceptual constraints.

${ }^{18}$ It is worth noting that, while contextualists face a parallel problem, the standard solutions to that problem won't help the standards pluralist. Hawthorne (2004) argues that contextualists licence the truth of 'abominable conjunctions' such as "Catriona knows that it is the fast train, but she may not assert that it is the fast train" because they disconnect the truth-conditions of knowledge ascriptions (which are tried to the context of utterance) from the propriety of assertion and practical reasoning (which is tied to the situation of the subject). Contextualists have dealt with this problem by 'explaining away' the propriety of these conjunctions (see Blome-Tillmann 2013). Because this solution is geared towards explaining linguistic data, it is of no use in dealing with Lynch's challenge. 
enjoys these rights when and only when one is under the jurisdiction of the legal system that recognises one as someone's legal guardian. For instance, imagine Catriona is recognised as Morven's legal guardian in country1, where she has adopted Morven together with her same-sex partner. While she lives in this country, she has various rights towards Morven. However, she takes a new job in country2, where same-sex adoption isn't legal, and so she is not recognised as Morven's legal guardian in country2. Thus, she lacks these rights in this new country.

The standards pluralist might suggest that we should think of knowledge as being a little like legal guardianship. So far I have talked as if individuals determine epistemic standards, and as if the standards pluralist holds there are as many knowledge relations as there are situations that individuals find themselves in, e.g. knowing relative to the standards of LOW, of HIGH, etc. But we could instead say that it is communities that determine epistemic standards. If this is right, then there are as many knowledge relations as there are distinct communities, and subjects may know relative to one community, but not know relative to another.

The underlying idea here is that each of us is a part of a complicated epistemic world. We move from epistemic community to epistemic community. In some of these communities, we enjoy rights that we lack in others. But these rights, and our implicit recognition of them, are key to our ability to navigate the world around us. Take Neil, a layperson who is reasonably well-informed about climate science, and the proposition that sea levels have risen 6.7 inches over the past century as a result of human-induced global warming ('SCARY' for short). ${ }^{19}$ Neil knows SCARY relative to the epistemic standards governing general public discourse about climate change, but he does not know SCARY relative to the rather more stringent standards governing scientific discourse. This means that, as a member of the general public, he need not inquire further into whether SCARY is true; he has done all that he needs. But, if he wanted to engage with the scientific community and enter into scientific discussion, he would need to do a lot more inquiring. Thus, that he knows relative to the standards governing public discourse means he enjoys a right- to terminate his inquiry-which obtains in a wide but still circumscribed range of situations. He enjoys this right when 'speaking as a member of the public', but would not enjoy it if he tried to present himself as a scientist.

\footnotetext{
${ }^{19}$ http://blogs.scientificamerican.com/cross-check/climate-change-facts-versus-opinions/
} 
If this works, the standards pluralist at least has the beginnings of a solution to the problem. Maybe she can't honour the letter of the platitudes ACT, ASS and INQ. But she can do justice to the idea that knowing that $p$ gives one certain rights in a wide range of situations. Remember that the Jacksonian methodology that Lynch's challenge appeals to permits modifying the platitudes. Of course, any modification must be independently motivated, and, in general, minor modifications are to be preferred to major modifications. But the case for standards pluralism provides some motivation for modifying the platitudes to fit with the standards pluralist's picture of knowledge, and I have just argued that the necessary modifications do some justice to the original idea behind the platitudes.

One might object that, while this might help with Lynch's challenge, it somewhat undermines the original motivations for standards pluralism. In particular, on any plausible account of what communities are, Hannah and Sarah are in the same community in both LOW and HIGH. So what about the argument that the standards pluralist can resolve this puzzle? I would like to make two points in response. First, even if the point is granted, this does not touch the standards pluralist solution to the second and third puzzles. The second puzzle concerns our conflicting 'sceptical' and 'anti-sceptical' intuitions. The standards pluralist response is that different communities may choose to favour more or less sceptical standards, depending on their particular needs, interests and purposes. The third puzzle concerns how the 'threshold' for knowledge is set. The standards pluralist response is that different communities may set the threshold in different places, also depending on their particular needs, interests and purposes.

Second, it is not clear that the point should be granted. The first puzzle is similar to the second and third in that it raises the question of where, precisely, the standards for knowledge should be set. Should they be set such that Hannah knows that the bank is open, or should they be set such that she does not know? Different communities may legitimately give different answers to this question. Which answer they give will depend on their needs, interests and purposes. For instance, are they often in 'high stakes' environments? Put very roughly, the more often a communities members find themselves in high stakes environments, the higher their standards for knowledge are likely to be.

\section{Concluding Remarks}

It is time to take stock. I have argued that one can construct a viable case for standards pluralism. This case, in large part, parallels the case for contextualism. I have also argued that, while neither 
view entails the other, standards pluralism and contextualism are mutually supporting: standards pluralism requires a non-standard semantics such as contextualism, and contextualism is good evidence for standards pluralism. I then turned to the case against standards pluralism. The basic problem is that standards pluralism posits knowledge relations that don't have the right kind of normative profile. This means it is unclear in what sense the standards pluralist offers us a theory of knowledge, rather than an elimination of knowledge. Finally, I gave a rough sketch of a standards pluralist response to this problem.

My aim in this paper has been to explore a neglected question: is there a single knowledge relation, or is there a plurality of knowledge relations? I have outlined both the case for thinking there is a plurality of knowledge relations, and the case against. I hope that this paper will lead to further work on how the considerations appealed to in favour of contextualism might be a reason to modify our metaphysical picture of knowledge, as well as a reason to modify our standard assumptions about the semantics of knowledge ascriptions. ${ }^{20}$

\section{References}

Alston, William. 1993. 'Epistemic Desiderata'. Philosophy and Phenomenological Research 53 (3): 52751.

- 2002. 'Truth: Concept and Property'. In What Is Truth?, 11-26. Berlin: Walter de Gruyter.

- 2005. Beyond Justification: Dimensions of Epistemic Evaluation. Ithaca: Cornell University Press.

Blome-Tillmann, Michael. 2013. 'Contextualism and the Knowledge Norms'. Pacific Philosophical Quarterly 94 (1): 89-100.

- 2014. Knowledge and Presuppositions. Oxford University Press.

Boghossian, Paul. 2006. Fear of Knowledge: Against Relativism and Constructivism. Oxford University Press.

BonJour, Laurence. 2010. 'The Myth of Knowledge'. Philosophical Perspectives 24 (1): 57-83.

\footnotetext{
${ }^{20}$ Thanks to Natalie Ashton, Delia Belleri, Tom Fery, Anna-Maria Asunta Eder, Michael Hannon, Dirk Kindermann, Katherina Kinzel, Anne-Kathrin Koch, Martin Kusch, Thomas Raleigh, Niels Wildschut and audiences in KU Leuven and Warwick. Research on this paper was assisted by funding from the ERC Advanced Grant Project "The Emergence of Relativism" (Grant No. 339382).
} 
Brogaard, Berit. 2008. 'In Defence of a Perspectival Semantics for "Know"'. Australasian Journal of Philosophy 86 (3): 439-59.

Brown, Jessica. 2006. 'Contextualism and Warranted Assertibility Manoeuvres'. Philosophical Studies 130 (3): 407-35.

- 2008a. 'Knowledge and Practical Reason'. Philosophy Compass 3 (6): 1135-52.

- 2008b. 'The Knowledge Norm for Assertion'. Philosophical Issues 18 (1): 89-103.

- 2013. 'Infallibilism, Evidence and Pragmatics'. Analysis 73 (4): 626-35.

Cohen, Stewart. 1999. 'Contextualism, Skepticism, and the Structure of Reasons'. Philosophical Perspectives 13: 57-89.

DeRose, Keith. 1992. 'Contextualism and Knowledge Attributions'. Philosophy and Phenomenological Research 52 (4): 913-29.

- 1995. 'Solving the Skeptical Problem'. Philosophical Review 104 (1): 1-52.

- 2009. The Case for Contextualism: Knowledge, Skepticism, and Context, Vol. 1. Oup Oxford.

Dretske, Fred. 2005. 'Is Knowledge Closed Under Known Entailment? The Case Against

Closure'. In Contemporary Debates in Epistemology, edited by Matthias Steup and Ernest Sosa, 13-26. Blackwell.

Fantl, Jeremy, and Matthew McGrath. 2009. Knowledge in an Uncertain World. Oxford University Press.

Gerken, Mikkel. 2011. 'Warrant and Action'. Synthese 178 (3): 529-47.

Grimm, Stephen R. 2015. 'Knowledge, Practical Interests, and Rising Tides’. In Epistemic Evaluation: Purposeful Epistemology, edited by John Greco and David Henderson. Oxford University Press.

Hannon, Michael. 2017. ‘A Solution to Knowledge's Threshold Problem'. Philosophical Studies 174 (3): 607-29.

Hawthorne, John. 2004. Knowledge and Lotteries. Oxford University Press.

Hawthorne, John, and Jason Stanley. 2008. 'Knowledge and Action'. Journal of Philosophy 105 (10): 571-90.

Jackson, Frank. 1998. From Metaphysics to Ethics: A Defence of Conceptual Analysis. Oxford University Press.

Kaplan, Mark. 1985. 'It's Not What You Know That Counts'. Journal of Philosophy 82 (7): 350-63. Kappel, Klemens. 2010. ‘On Saying That Someone Knows: Themes from Craig'. In Social Epistemology, edited by Adrian Haddock, Alan Millar, and Duncan Pritchard. Oxford University Press. 
Kelp, Christoph. 2011. 'What's the Point of “Knowledge” Anyway?' Episteme 8 (1): 53-66.

Kompa, Nikola. 2002. 'The Context Sensitivity of Knowledge Ascriptions’. Grazer Philosophische Studien 64 (1): 1-18.

Kusch, Martin. forthcoming. 'Epistemic Relativism, Scepticism, Pluralism'. Synthese, 1-17.

Lackey, Jennifer. 2007. 'Norms of Assertion'. Noûs 41 (4): 594-626.

Lawlor, Krista. 2013. Assurance: An Austinian View of Knowledge and Knowledge Claims. Oxford University Press.

Lewis, David. 1996. 'Elusive Knowledge'. Australasian Journal of Philosophy 74 (4): 549-67.

Lynch, Michael. 2009. Truth as One and Many. Clarendon Press.

- 2013. ‘Three Questions for Truth Pluralism'. In Truth and Pluralism: Current Debates, edited by Nikolaj Jang Lee Linding Pedersen and Cory D. Wright, 21-41. Oxford University Press.

MacFarlane, John. 2009. 'Nonindexical Contextualism'. Synthese 166 (2): 231-50.

- 2014. Assessment Sensitivity: Relative Truth and Its Applications. Oxford University Press.

Nagel, Jennifer. 2008. 'Knowledge Ascriptions and the Psychological Consequences of Changing Stakes'. Australasian Journal of Philosophy 86 (2): 279-94.

Pedersen, Nikolaj Jang Lee Linding, and Cory D. Wright, eds. 2013. Truth and Pluralism: Current Debates. Oxford University Press.

Rorty, Richard. 1995. 'Is Truth a Goal of Enquiry? Davidson vs. Wright'. Philosophical Quarterly 45 (180): 281-300.

Rysiew, Patrick. 2001. 'The Context-Sensitivity of Knowledge Attributions'. Noûs 35 (4): 477514.

- 2012. 'Epistemic Scorekeeping'. In Knowledge Ascriptions, edited by Jessica Brown and Mikkel Gerken. Oxford University Press.

Schaffer, Jonathan. 2004a. 'From Contextualism to Contrastivism'. Philosophical Studies 119 (1-2): 73-104.

—. 2004b. 'Skepticism, Contextualism, and Discrimination'. Philosophy and Phenomenological Research 69 (1): 138-155.

Schaffer, Jonathan, and Zoltan Gendler Szabo. 2013. 'Epistemic Comparativism: A Contextualist Semantics for Knowledge Ascriptions'. Philosophical Studies, no. 2: 1-53.

Seidel, Markus. 2014. Epistemic Relativism. A Constructive Critique. Palgrave-Macmillan.

Sosa, Ernest. 2007. A Virtue Epistemology: Apt Belief and Reflective Knowledge, Volume I. Oxford University Press. 
- 2009. Reflective Knowledge: Apt Belief and Reflective Knowledge, Volume II. Oxford University Press.

Stanley, Jason. 2005. Knowledge and Practical Interests. Oxford University Press.

- 2011. Know How. Oxford University Press.

Williams, Michael. 2007. 'Why (Wittgensteinian) Contextualism Is Not Relativism'. Episteme 4 (1): 93-114.

Williamson, Timothy. 2000. Knowledge and Its Limits. Oxford University Press.

- 2005. 'Knowledge, Context, and the Agent's Point of View'. In Contextualism in Philosophy: Knowledge, Meaning, and Truth, edited by Gerhard Preyer and Georg Peter, 91114. Oxford University Press.

Wright, Crispin. 1992. Truth and Objectivity. Harvard University Press.

- 1996. 'Precis of "Truth and Objectivity" and Response to Commentators'. Philosophy and Phenomenological Research 56 (4): 911-41. 